BMJ Open

Diabetes

Research

\& Care

\title{
GOAL study: clinical and non-clinical predictive factors for achieving glycemic control in people with type 2 diabetes in real clinical practice
}

\author{
Abdulqawi Al Mansari, ${ }^{1}$ Youssef Obeid, ${ }^{2}$ Najmul Islam, ${ }^{3}$ Mohammed Fariduddin, ${ }^{4}$ \\ Ahmed Hassoun, ${ }^{5}$ Khier Djaballah, ${ }^{6}$ Mojtaba Malek, ${ }^{7}$ Dror Dicker, ${ }^{8}$ \\ Tirthankar Chaudhury ${ }^{9}$
}

To cite: Al Mansari A, Obeid Y, Islam N, et al. GOAL study: clinical and nonclinical predictive factors for achieving glycemic control in people with type 2 diabetes in real clinical practice. BMJ Open Diab Res Care 2018;6:e000519. doi:10.1136/ bmjdrc-2018-000519

- Additional material is published online only. To view please visit the journal online (http://dx.doi.org/10.1136/ bmjdrc-2018-000519).

Abstract of GOAL study results was published at the 77th American Diabetes Association Scientific session in 9-13 June 2017 (No. 2359-PUB).

Received 25 January 2018 Revised 23 May 2018 Accepted 13 June 2018

Check for updates

C Author(s) (or their employer(s)) 2018. Re-use permitted under CC BY-NC. No commercial re-use. See rights and permissions. Published by BMJ.

For numbered affiliations see end of article.

Correspondence to Dr Tirthankar Chaudhury; tchaudhury67@yahoo.co.uk

\section{ABSTRACT}

Objective The American Diabetes Association and the European Association for the Study of Diabetes guidelines recommend to individualize treatment targets/strategies in inadequately controlled patients by lifestyle management and glucose-lowering drugs to decrease the burden of diabetes-related complications. This real-world practice study aimed to assess predictive factors for achieving the glycemic hemoglobin A1C (HbA1C) at 6 months as targeted by the treating physician in adults with type 2 diabetes who required initiation of basal insulin, initiation of bolus insulin, or modification from basal or premixed insulin to new insulin regimen containing insulin glargine and/or insulin glulisine.

Research design and methods This was an international, multicenter, observational survey with 12-month follow-up time in adults with type 2 diabetes inadequately controlled conducted in 10 developing countries.

Results Overall, 2704 patients (mean age: 54.6 years, body mass index: $28.7 \mathrm{~kg} / \mathrm{m}^{2}$; Caucasian: $46.1 \%$, type 2 diabetes duration: 10.1 years) with poor glycemic control (mean HbA1c: 9.7\% (83 mmol/mol), fasting blood glucose: $196.8 \mathrm{mg} / \mathrm{dL}$ ) were eligible. At 6 months, advanced age, Caucasian ethnicity, shorter type 2 diabetes duration ( $>10$ vs 1 year, $p<0.0001$ ), lower baseline $\mathrm{HbA1c}(\geq 8.5 \%$ vs $<7 \%, \mathrm{p}<0.0001)$ and no intake of oral antidiabetic drug (OAD) (none vs $2, p=0.02$ ) were predictive factors for achieving glycemic goal as targeted by the treating physician. Absolute changes in the mean $\mathrm{HbA1c}$ of $-1.7 \%$ and $-2 \%$ were observed from baseline to 6 and 12 months, respectively.

Conclusions Along with some well-known predictive factors, this study suggested that early insulin regimen treatment initiation and/or intensification allowed patients to promote glycemic control.

\section{INTRODUCTION}

Diabetes is one of the major health priority of the 21 st century ${ }^{1}$ causing 1.5 million deaths in $2012 .^{2}$ It is expected that by $2025-2030$, there will be 380 million people with type 2 diabetes, ${ }^{3}$ and this pathology will move up to the seventh leading cause of death worldwide. ${ }^{4}$ Diabetes is recognized as a well-known

\section{Significance of the study}

What is already known about this subject?

- Adequate glycemic control and identification of risk factors may prevent the development of cardiovascular complications in type 2 diabetes.

What are the new findings?

- Our study identified predictive factors for achieving glycemic goal as targeted by the treating physician and showed that patients with type 2 diabetes inadequately controlled starting or intensifying their insulin dosing regimen achieved a significant decrease in glycemic hemoglobin A1 at 6 and 12 months compared with baseline.

How might these results change the focus of research or clinical practice?

- To avoid clinical inertia in clinical practice contributing to patients with type 2 diabetes living with suboptimal glycemic control for a long time, further potential approaches including fundamental changes in medical care should be studied.

risk factor for cardiovascular diseases (CVDs), responsible for about a twofold excess risk for various vascular diseases such as coronary heart diseases (CHD), strokes, and other vascular deaths. ${ }^{5}$

Type 2 diabetes requires the adoption of a healthy diet, physical activity and maintenance of a normal body weight. But, the cornerstone of type 2 diabetes treatment includes oral antidiabetic drugs (OADs) and insulin use in the event of increased glycemia.

The American Diabetes Association (ADA) and the European Association for the Study of Diabetes (EASD) consensus ${ }^{6}$ for the management of type 2 diabetes recommends a glycemic target hemoglobin A1c (HbA1c) $<7 \% \quad(53 \mathrm{mmol} / \mathrm{mol}) .^{7}$ The UK Prospective Diabetes Study (UKPDS) showed 
that each $1 \%$ reduction in $\mathrm{HbA1c}$ is associated with a risk reduction of complications that is clinically and statistically significant. ${ }^{8}$ After adjusting for multiple potential confounding factors, $1 \%$ rise in HbAlc was associated with a $7 \%$ increase in the risk of a first major CV event, a $12 \%$ rise in the risk of death, a $20 \%$ rise in the risk of heart failure. ${ }^{9}$ The goal of therapy for the majority of people with diabetes is to prevent CV events by achieving a sustained glycemic control (HbAlc $<7 \%$ (53 mmol/ mol) ). ${ }^{6}$ The choice of the medications used to achieve glycemic goals must be individualized for each patient and adjusted as diabetes is a progressive disease. When lifestyle, metformin, and sulfonylurea or basal insulin are insufficient and do not lead to a glycemic control, the next step should be an initiation or intensification of insulin therapy including additional injections of short-acting or rapid-acting insulins. ${ }^{6}$ Despite an availability of a range of pharmacological agents and the stepwise approach to type 2 diabetes treatment advocated by ADA/EASD position statement, ${ }^{10}$ many patients with type 2 diabetes remain in poor glycemic control for prolonged periods of time. ${ }^{11}$

The aim of the present study was to assess the clinical and non-clinical predictive factors for achieving the glycemic goal HbAlc as targeted by the treating physician in adults with type 2 diabetes requiring insulin initiation, titration, and/or intensification.

\section{RESEARCH DESIGN AND METHODS \\ Study design}

This was a 12 months real-world practice, multicenter, non-interventional, non-comparative study conducted in adults ( $>18$ years) with type 2 diabetes inadequately controlled. In the context of the usual clinical practice, four visits were scheduled: at baseline (Visit 1 (V1)), and at 3 (V2), 6 (V3) and 12 months (V4) of follow-up (at the end of the study period). Participating physicians were, then, asked to record data for study endpoint assessments at baseline, every 3 months ( \pm 1 week) for the first 6 months, and then at 1 year through the observation period from treatment start and at the end of study. The estimated duration of the survey was 2 years.

\section{Study setting}

The study was carried out from October 2012 to January 2015 in 10 developing countries from Africa (Egypt, South Africa), Middle East (Israel, Saudi Arabia, United Arab Emirates, Iran and Lebanon) and South Asia (Bangladesh, India and Pakistan).

\section{Physician selection}

The number of physicians who participated in the study as well as their profile were determined on a country basis. HbA1c control was part of the center selection criteria. The target number of participating sites was 150 involving general practitioners (GPs) and diabetologists. Of the 198 participating physicians, 180 were active with the highest enrolment in South Asia (1509 patients and
58 physicians) and the lowest enrollment in Africa (710 patients and 42 physicians).

\section{Patient selection}

Each physician included patients until the targeted number of patients in his/her country was reached. A screening log was implemented to document this consecutive enrolment. As 1949 patients needed to be included, it was planned to recruit 2900 patients with a minimum of 100 patients by countries or region.

\section{Study population}

Patients meeting the following inclusion criteria were proposed to be included in this study: male and female, aged over 18 years, with a known and inadequately controlled type 2 diabetes because the glycemic goal targeted by the treating physician was not achieved, for whom treating physician had decided an initiation of adjunct therapy with basal insulin glargine or an adjustment of the current insulin therapy: either basal insulin or premixed insulin were switched to insulin glargine alone, or insulin glulisine and basal insulin, or insulin glargine and insulin glulisine. Conversely, patients with history of hypersensitivity to insulin glargine and/ or insulin glulisine, pregnant women, or women with breast feeding, or of childbearing potential not using efficient contraception, patients with brittle diabetes, psychiatric or mental diseases, unable or unwilling to manage properly the basal bolus regimen were excluded from the study.

\section{Study treatments}

This was a product registry in which subcutaneous injectable solutions of insulin glargine \pm insulin glulisine were administered in routine clinical practice according to the approved indication. According to the physician's opinion and independently from study entry, the patients who were enrolled in the study were decided to initiate a basal insulin therapy with insulin glargine, or to modify the existing basal insulin therapy by switching to insulin glargine, or to add insulin glulisine to basal insulin, or to initiate a new insulin dosing regimen with insulin glargine and insulin glulisine from premixed insulin. The dosage and timing of dose of insulin glargine was to be individually adjusted. The dose of insulin glargine was to be titrated based on the fasting (pre-breakfast) capillary plasma glucose (FPG) levels. In case of prescription of insulin glargine and insulin glulisine, the dosage of insulin glulisine was individually adjusted and titrated according to postprandial capillary plasma glucose level (PPG) and either to the carbohydrate content of the meal following calculation with carbohydrate $(\mathrm{CHO})$ ratio. The estimated average treatment duration was 12 months.

\section{Data collection}

Data were reported on structured and strictly anonymous questionnaires (case report forms) for eligible patients. At inclusion, collected data included demographic and 
socioeconomic characteristics, relevant medical history, including diabetes complications, CV risk factors, glycemic control (blood glucose monitoring, self-monitoring blood glucose (SMBG), HbA1c, hypoglycemia), vital signs, reason(s) to add-on an insulin therapy to OADs/change in insulin therapy, patient's glycemic goal targeted by the treating physician, life style, antidiabetic therapy at the time and at the end of the visit (ie, all type of antidiabetics including glucagon-like peptide-1 analog). HbA1c laboratory measurement was performed at each visit: at baseline, at 3 months, at 6 months, and at 12 months (end of study) from inclusion. At each follow-up visit (after 3, 6, or 12 months of treatment(s)), symptomatic hypoglycemic episodes (including time information, adverse drug reaction (ADR), vital signs, HbA1c, FPG and PPG monitoring (if available), and antidiabetic therapy at the time and at the end of the visit) were recorded by the physicians. Severe symptomatic hypoglycemia was reported as an event with clinical symptoms that were considered to result from hypoglycemia, needing third party help with plasma glucose $(\mathrm{PG})<36 \mathrm{mg} / \mathrm{dL}(2 \mathrm{mmol} / \mathrm{L})$ or countermeasure (oral carbohydrate/glucagon/intravenous glucose) leading to recovery attributable to the restoration of PG to normal. Serious hypoglycemia was defined as hypoglycemia with at least one of the following items: loss of consciousness, seizure, patients undergoing emergency department, or symptoms that fulfilled serious ADR criteria.

\section{Statistical analysis}

All data were analysed using SAS (V.8.2 or higher). Descriptive analyses and statistical tests $\left(\chi^{2}\right.$ test, Fisher test, t-test, Wilcoxon Mann-Whitney test, Wilcoxon test) were used as appropriate. Statistical analyses were performed at the $5 \%$ global significance level using two-sided tests.

Univariate and multivariate logistic regression analyses were performed to identify clinical and non-clinical predictive factors for achieving glycemic control (HbAlc level targeted by the physician) at 6 and 12 months. Univariate OR was presented with its 95\% CI. All significant variables in univariate statistical test at the 0.20 level were included in the multivariate initial model. A stepwise procedure was used with an entrance significance level at 20\% and a removed significance level at 5\%. The final model was constructed with the selected variables and adjusted OR with 95\% CI were provided.

\section{Ethical considerations}

This registry was conducted in accordance with the ethical principles laid down by the Declaration of Helsinki, all international applicable guidelines, national laws and regulations of each country. The physician fully informed the patient using appropriate language about the aim and objectives of the study, and written informed consent was provided by participants. Appropriate measures were taken to ensure the confidentiality of the data. The study was coordinated by a leading diabetologist located in the following countries: Bangladesh, Iran, Israel, Lebanon, Pakistan, Saudia Arabia, and United Arab Emirates.

\section{RESULTS}

During the recruitment period, 3173 patients were included in the study and 2704 eligible patients were analysed at baseline (figure 1). The study was completed by 2324 patients corresponding to $73.2 \%$ of included patients.

\section{Sociodemographic characteristics}

More than half of the patients were males (53.5\%) (table 1).

The mean age was $54.6 \pm 10.6$ years with a range from 19 to 90 years. The majority $(75.1 \%)$ of patients belonged to the 40-65 years age class. Most patients were of South Asian $(48.8 \%)$ or Oriental, Arab, Persian (40.6\%) ethnicities.

\section{Medical history}

On average, diabetes was diagnosed since a median time of 9 years and affected two or three generations in $48.4 \%$ of patients. The mean baseline BMI was $28.7 \pm 5.4 \mathrm{~kg} /$ $\mathrm{m}^{2}$. A total of 1512 patients $(55.9 \%)$ had any diabetes-related CV complications; $87.9 \%$ suffering from microvascular and $32.9 \%$ from macrovascular CV complications. The most common diabetes-related complications were sensory neuropathy (53.8\%) (online supplementary figure S1).

\section{CV risk factors}

The 10-year CHD risk rate was estimated at $18.7 \% \pm 14.5 \%$ (median: 14.6\%) (table 1). Most patients had uncontrolled blood pressure (BP): $62.9 \%$ had systolic $\mathrm{BP} \geq 130$ $\mathrm{mm} \mathrm{Hg}$ and $72.9 \%$ had diastolic $\mathrm{BP} \geq 80 \mathrm{~mm} \mathrm{Hg}$.

\section{Antidiabetic therapy}

At the time of inclusion visit, $63.3 \%$ of patients were treated by $\mathrm{OAD}$ alone, $8.8 \%$ by insulin alone and $27.9 \%$ by $\mathrm{OAD}+$ insulin. Biguanide combined with sulfonylureas were the most frequently used OADs $(23.2 \%)$. Among insulin-treated patients, $38.8 \%, 35.6 \%$ and $17.1 \%$ were receiving basal insulin alone, premix insulin and basal+prandial insulin respectively (online supplementary figure S2). At the end of the inclusion visit, antidiabetic therapy had been intensified by the physician if necessary. Thus, $85.4 \%$ of patients were prescribed both $\mathrm{OAD}$ and insulin, and $14.6 \%$ received insulin injectable alone. Regarding the insulin treatment prescribed, $71.2 \%$ received basal insulin alone; insulin glargine being the most frequent $(96.0 \%)$.

\section{Glycemic control and self-management}

Among the 2596 patients with available tests performed in the last 3 months before the inclusion visit, the mean HbA1c level was $9.7 \% \pm 1.8 \%(\approx 83 \mathrm{mmol} / \mathrm{mol})$. Only $2.2 \%$ of the patients were achieving an $\mathrm{HbAlc}<7 \%$ (53 mmol/ mol). Regarding the glycemic goals, the HbA1c targeted 


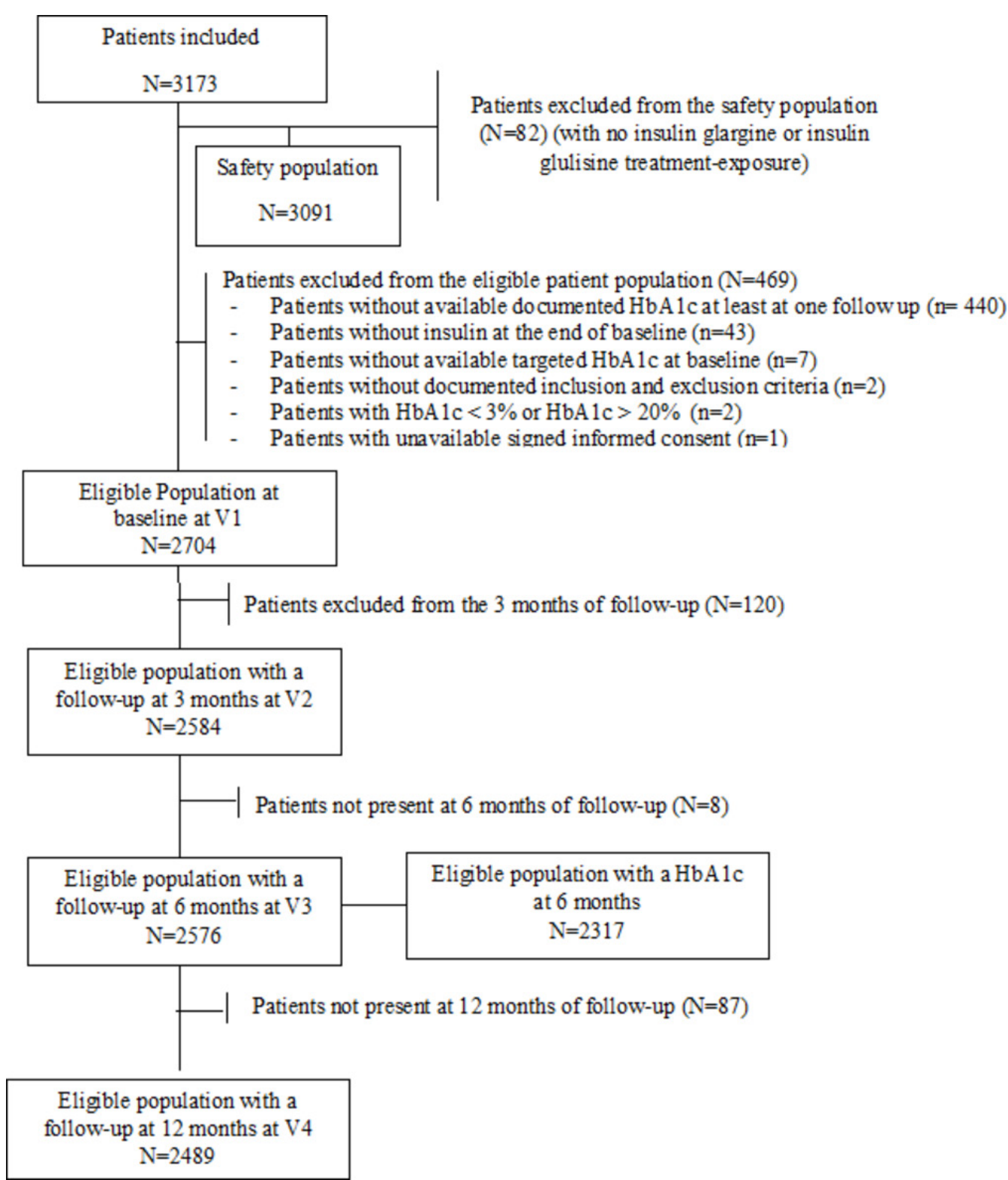

Figure 1 Disposition of patients time windows: follow-up at 3 months: (2-4.5 months) after baseline; follow-up at 6 months: (4.5-9 months) after baseline; follow-up at 12 months: >9 months after baseline. HbA1c, glycemic hemoglobin A1c.

by the treating physician was $<7 \%$ for $25.8 \%$ ( $\mathrm{n}=698$ ) of patients with a mean FPG of $116 \mathrm{mg} / \mathrm{dL}$ and a PPG of 157 $\mathrm{mg} / \mathrm{dL}$. For the rest of the population, the glycemic goals decided by the treating physician were $7 \%-7.5 \%$ in $60.5 \%$ of patients and $\geq 7.5 \%$ in $13.7 \%$. About a quarter $(26.8 \%)$ and $69.0 \%$ of patients did not have any follow-up visit by a diabetologist or a GP, respectively. Overall, $36.3 \%$ did not receive any diabetes education, $91.9 \%$ self-monitor their blood glucose regularly, and $51.5 \%$ followed a healthy diet and exercise plan.

\section{Predictive factors for achieving HbA1c targeted by the physician at 6 months}

The clinical variables relative to age, ethnicity, history of diabetes, presence of any diabetes-related complications, baseline level of HbAlc, insulin use as well as the non-clinical variables relative to diabetes education, frequency of HbA1c level measurement, and medical health coverage were significant and considered for multivariate analysis (table 2). The multivariate logistic regression analysis showed that higher age, Caucasian ethnicity, shorter duration of diabetes, and lower baseline $\mathrm{HbAlc}$ were predictors for achieving glycemic goal $(\mathrm{HbAlc}<7 \%)$ as targeted by the treating physician. Conversely, combination therapy of OADs ( $>2$ OADs) and use of analog insulin were predictors of poor glycemic control.

The univariate analysis performed at 12 months identified the same significant variables found at 6 months. In addition, patients diagnosed with high blood pressure (HBP) (OR 0.8; $\mathrm{p}=0.0207$ ), taking at least one OAD (OR $0.8 ; \mathrm{p}<0.0001)$, or following a healthy diet and exercise plan (OR $0.8 ; \mathrm{p}=0.0012$ ) were slightly more likely to fail 
Table 1 Sociodemographic characteristics of eligible patients with type 2 diabetes at baseline

\begin{tabular}{|c|c|c|}
\hline Demographics & & $\begin{array}{l}\text { Eligible patient } \\
\text { population } \\
(\mathrm{N}=2704)\end{array}$ \\
\hline \multirow[t]{2}{*}{ Age (years) } & $\mathrm{N}$ (missing) & $2704(0)$ \\
\hline & Mean (SD) & $54.6(10.6)$ \\
\hline \multirow[t]{2}{*}{ Male (n, \%) } & $\mathrm{N}$ (missing) & $2704(0)$ \\
\hline & n (\%) & $1446(53.5 \%)$ \\
\hline \multirow[t]{3}{*}{ Ethnicity (n, \%) } & $\mathrm{N}$ (missing) & $2704(0)$ \\
\hline & Caucasian* & $1246(46.1 \%)$ \\
\hline & Non-Caucasian & $1458(53.9 \%)$ \\
\hline \multirow[t]{5}{*}{ Education level (n, \%) } & $\mathrm{N}$ (missing) & $2702(2)$ \\
\hline & Illiterate & $172(6.4 \%)$ \\
\hline & Primary & $491(18.2 \%)$ \\
\hline & Secondary & 916 (33.9\%) \\
\hline & $\begin{array}{l}\text { University/higher } \\
\text { education }\end{array}$ & $1123(41.6 \%)$ \\
\hline \multirow{2}{*}{$\begin{array}{l}\text { Medical health coverage ( } \mathrm{n} \text {, } \\
\%)\end{array}$} & $\mathrm{N}$ (missing) & $2703(1)$ \\
\hline & $\mathrm{n}(\%)$ & $1413(52.3 \%)$ \\
\hline \multirow[t]{4}{*}{ Employment status (n, \%) } & $\mathrm{N}$ (missing) & $2704(0)$ \\
\hline & Full time & $1194(44.2 \%)$ \\
\hline & Part time & $131(4.8 \%)$ \\
\hline & Unemployed & 1379 (51.0\%) \\
\hline \multirow[t]{2}{*}{ Weight (kg) } & $\mathrm{N}$ (missing) & $2688(16)$ \\
\hline & m (SD) & $78.3(16.2)$ \\
\hline \multirow[t]{2}{*}{ BMI $\left(\mathrm{kg} / \mathrm{m}^{2}\right)$} & $\mathrm{N}$ (missing) & $2641(63)$ \\
\hline & Mean (SD) & $28.7(5.4)$ \\
\hline \multirow[t]{2}{*}{ Duration of diabetes (year) } & $\mathrm{N}$ (missing) & $2692(12)$ \\
\hline & Mean (SD) & $10.1(6.7)$ \\
\hline \multirow{2}{*}{$\begin{array}{l}\text { Diabetes-related complication } \\
(\mathrm{n}, \%)\end{array}$} & $\mathrm{N}$ (missing) & $2704(0)$ \\
\hline & n (\%) & $1512(55.9 \%)$ \\
\hline \multirow{2}{*}{$\begin{array}{l}\text { At least one macrovascular } \\
\text { complication }\end{array}$} & $\mathrm{N}$ & 1512 \\
\hline & $n(\%)$ & 498 (32.9\%) \\
\hline \multirow{2}{*}{$\begin{array}{l}\text { At least one microvascular } \\
\text { complication }\end{array}$} & $\mathrm{N}$ & 1512 \\
\hline & $\mathrm{n}(\%)$ & $1329(87.9 \%)$ \\
\hline \multirow[t]{2}{*}{10 years CV risk (\%) } & $N$ (missing) & $1683(1021)$ \\
\hline & Median & 14.6 \\
\hline \multirow{3}{*}{$\begin{array}{l}\text { Diagnosis of high blood } \\
\text { pressure }(n, \%)\end{array}$} & $\mathrm{N}$ (missing) & $2702(2)$ \\
\hline & Yes & $1657(61.3 \%)$ \\
\hline & No / Unknown & $1045(38.7 \%)$ \\
\hline \multirow{3}{*}{$\begin{array}{l}\text { Diagnosis of dyslipidemia ( } \mathrm{n} \text {, } \\
\%)\end{array}$} & $\mathrm{N}$ (missing) & 2702 (2) \\
\hline & Yes & 1603 (59.3\%) \\
\hline & No/Unknown & $1099(40.7 \%)$ \\
\hline \multirow[t]{4}{*}{ Smoking habits (n, \%) } & $\mathrm{N}$ (missing) & 2701 (3) \\
\hline & Never & $1960(72.6 \%)$ \\
\hline & Former & 403 (14.9\%) \\
\hline & Current & 338 (12.5\%) \\
\hline \multirow{2}{*}{$\begin{array}{l}\text { Last } \mathrm{HbA1c} \text { level in the last } 3 \\
\text { months (\%) }\end{array}$} & $\mathrm{N}$ (missing) & $2596(108)$ \\
\hline & Mean (SD) & $9.7(1.8)$ \\
\hline
\end{tabular}

Continued

\section{Table 1 Continued}

\begin{tabular}{llc}
\hline Demographics & & $\begin{array}{l}\text { Eligible patient } \\
\text { population } \\
\text { (N=2704) }\end{array}$ \\
\hline $\begin{array}{ll}\mathrm{HbA1c} \text { level in the last } 3 \\
\text { months in classes (\%) }\end{array}$ & $\mathrm{N}$ (missing) & $2596(108)$ \\
& $<7 \%$ & $58(2.2 \%)$ \\
& $7-7.5 \%$ & $97(3.7 \%)$ \\
& $7.5-8 \%$ & $226(8.7 \%)$ \\
& $8-8.5 \%$ & $321(12.4 \%)$ \\
& $\geq 8.5 \%$ & $1884(73.0 \%)$ \\
\hline
\end{tabular}

${ }^{*}$ Caucasian class included Caucasian and Oriental/Arab/Persian patients, as Caucasians were classified as individuals having origins from Europe, the Middle East, or North Africa. ${ }^{40}$

$\mathrm{BMI}$, body mass index; CV, cardiovascular; $\mathrm{HbA1c}$, glycemic hemoglobin A1c.

to achieve HbA1c targeted by the physician at 12 months (online supplementary table S1).

\section{Analysis of $\mathrm{HbA1c}$}

Table 3 reports the variables of interest the treating physician would have considered for the determination of that glycemic target. The glycemic control improved along the course of the study (figure 2). In average, after 6 and 12 months of treatment, a mean absolute change in HbA1c of $-1.7 \%(95 \% \mathrm{CI}-1.7 \%$ to $-1.6 \%)$ and $-2 \%(95 \% \mathrm{CI}$ $-2.1 \%$ to $-2.0 \%$ ) was observed from baseline, respectively. Similarly, the proportion of patients achieving HbAlc target $<7 \%$ ( $53 \mathrm{mmol} / \mathrm{mol}$ ) increased from $19.0 \%$ $(\mathrm{n}=440)$ at 6 months to $29.7 \% \quad(\mathrm{n}=684)$ at 12 months. Therefore, a large proportion of individuals $(98.0 \%$, 684/698) with a lower HbAlc goal achieved their HbAlc target at the end of study.

\section{Hypoglycemia}

Among the 3091 patients included in the safety population, 223 patients $(7.2 \%)$ experienced a symptomatic episode of hypoglycemia. Overall, nocturnal or severe hypoglycemia (2.4\% and $1.2 \%$, respectively) was infrequent at the end of the study. According to the physician's opinion, only three patients $(0.1 \%)$ were exposed to a serious episode of hypoglycemia.

\section{ADRs and deaths}

A total of 18 patients experienced at least one ADR $(0.6 \%) ; 14$ out of 18 patients were treated with insulin glargine. A total of 20 events with ADR were reported; the most commonly reported ADR was hypoglycemia $(0.3 \%)$. Among all ADR, six serious ADR were reported in six patients $(0.2 \%)$ : two hypoglycemias, one chest pain, one death of unspecified etiology, meningitis found in five patients receiving basal insulin glargine and one hyperglycemia reported in one patient taking insulin glulisine. Basal insulin glargine was discontinued in two patients $(0.1 \%)$ because of the occurrence of ADR: one injection site reaction and one meningitis. In total, there were eight deaths including one fatal ADR. 
Table 2 Variables identified in the univariate and multivariate analyses for clinical and non-clinical factors as predictors of $\mathrm{HbA1c}$ goal as targeted by the treating physician at 6 months

\begin{tabular}{|c|c|c|c|c|c|c|c|}
\hline & \multirow[b]{2}{*}{ Effect } & \multicolumn{3}{|c|}{ Univariate analysis* } & \multicolumn{3}{|c|}{ Multivariate analysis* } \\
\hline & & OR & $95 \% \mathrm{Cl}$ & $P$ values & OR & $95 \% \mathrm{Cl}$ & $P$ values \\
\hline \multicolumn{8}{|l|}{ Clinical variables } \\
\hline Age & Age & 1.012 & 1.003 to 1.022 & 0.0050 & 1.024 & 1.012 to 1.036 & 0.0001 \\
\hline Ethnicity & $\begin{array}{l}\text { Non-Caucasian } \\
\text { versus Caucasian }\end{array}$ & 0.628 & 0.513 to 0.768 & $<0.0001$ & 0.528 & 0.412 to 0.677 & $<0.0001$ \\
\hline \multirow{3}{*}{$\begin{array}{l}\text { Diabetes duration in class } \\
\text { (years) }\end{array}$} & $>10$ versus $\leq 1$ & 0.440 & 0.304 to 0.639 & $<0.0001$ & 0.320 & 0.197 to 0.519 & $<0.0001$ \\
\hline & $5-10$ versus $\leq 1$ & 0.482 & 0.329 to 0.705 & & 0.361 & 0.223 to 0.586 & $<0.0001$ \\
\hline & $1-5$ versus $\leq 1$ & 0.650 & 0.439 to 0.962 & & 0.574 & 0.355 to 0.930 & 0.0240 \\
\hline \multirow{2}{*}{$\begin{array}{l}\text { Diabetes affecting two or } \\
\text { three generations }\end{array}$} & Yes versus no & 1.444 & 1.137 to 1.834 & 0.0023 & 1.556 & 1.173 to 2.065 & 0.0022 \\
\hline & Unknown versus no & 1.024 & 0.758 to 1.383 & & 1.134 & 0.787 to 1.634 & 0.4991 \\
\hline \multirow{2}{*}{$\begin{array}{l}\text { Any diabetes-related } \\
\text { complications }\end{array}$} & Yes versus no & 0.926 & 0.751 to 1.141 & 0.0118 & 0.872 & 0.676 to 1.123 & 0.2887 \\
\hline & Unknown versus no & 1.835 & 1.153 to 2.922 & & 2.046 & 1.137 to 3.681 & 0.0169 \\
\hline \multirow{4}{*}{$\begin{array}{l}\mathrm{HbA1c} \text { at baseline (five } \\
\text { classes) }\end{array}$} & $\geq 8.5 \%$ versus $<7 \%$ & 0.167 & 0.093 to 0.299 & $<0.0001$ & 0.173 & 0.091 to 0.326 & $<0.0001$ \\
\hline & $8-8.5 \%$ versus $<7 \%$ & 0.254 & 0.135 to 0.477 & & 0.270 & 0.135 to 0.539 & 0.0002 \\
\hline & $7.5-8 \%$ versus $<7 \%$ & 0.487 & 0.256 to 0.923 & & 0.511 & 0.254 to 1.029 & 0.0602 \\
\hline & $7-7.5 \%$ versus $<7 \%$ & 0.612 & 0.298 to 1.256 & & 0.799 & 0.362 to 1.764 & 0.5791 \\
\hline \multicolumn{8}{|c|}{ Antidiabetics taken at the end of inclusion } \\
\hline Route of treatments & $\begin{array}{l}\text { Oral+injectable versus } \\
\text { injectable }\end{array}$ & 0.717 & 0.545 to 0.944 & 0.0288 & & & \\
\hline Analog insulin & Yes versus no & 0.481 & 0.243 to 0.951 & 0.0314 & 0.351 & 0.142 to 0.870 & 0.0238 \\
\hline \multirow[t]{3}{*}{ Number of OADs taken } & $>2$ versus none & 0.390 & 0.246 to 0.620 & 0.0705 & 0.531 & 0.311 to 0.905 & 0.0200 \\
\hline & 2 versus none & 0.822 & 0.611 to 1.106 & & 0.982 & 0.683 to 1.412 & 0.9235 \\
\hline & 1 versus none & 0.713 & 0.528 to 0.964 & & 0.781 & 0.540 to 1.131 & 0.1913 \\
\hline \multicolumn{8}{|l|}{$\begin{array}{l}\text { Reasons to add insulin } \\
\text { therapy to OADs }\end{array}$} \\
\hline $\begin{array}{l}\text { HbA1c target not } \\
\text { achieved }\end{array}$ & Yes versus no & 0.669 & 0.504 to 0.888 & 0.0053 & & & \\
\hline FPG target not achieved & Yes versus no & 0.777 & 0.622 to 0.971 & 0.0260 & & & \\
\hline \multicolumn{8}{|c|}{ Non-clinical variables } \\
\hline $\begin{array}{l}\text { Receiving diabetes } \\
\text { education }\end{array}$ & Yes versus no & 0.792 & 0.644 to 0.974 & 0.0269 & & & \\
\hline \multirow{3}{*}{$\begin{array}{l}\text { Frequency of tests during } \\
\text { past year in class }\end{array}$} & $\geq 3$ versus 0 & 1.121 & 0.299 to 4.202 & 0.0037 & & & \\
\hline & 2 versus 0 & 0.717 & 0.191 to 2.688 & & & & \\
\hline & 1 versus 0 & 0.705 & 0.188 to 2.637 & & & & \\
\hline Medical health coverage & Yes versus no & 1.277 & 1.043 to 1.562 & 0.0175 & & & \\
\hline
\end{tabular}

Predictive factors for achieving $\mathrm{HbA} 1 \mathrm{c}$ targeted by the physician at 12 months.

${ }^{*}$ All variables were significant in univariate statistical test at 0.20 level. ORs were estimated with two-sided $95 \%$ Cls with univariate logistic regressions. Stepwise selection; decision criteria to enter in the multivariate analysis: $\chi^{2}$ with significant level at 0.20 , to stay: Wald $\chi^{2}$ with significant level at 0.05 .

FPG, fasting plasma glucose; HbA1c, glycemic hemoglobin A1c; OAD, oral antidiabetic.

There were no marked changes in weight, BMI, systolic and diastolic BP from baseline to the end of the survey.

\section{CONCLUSIONS}

The eligible study population was large including a high number of patients $(n=2704)$ with 1 year of follow-up who remained uncontrolled despite the use of antidiabetics and also insulin. The baseline characteristics of the patients were similar to those observed in the International Diabetes Management Practices Survey (IDMPS) as far as age, gender, duration of diabetes, level of glycemic control, comorbidity (HBP and dyslipidemia), and exposure to any diabetes related complications were concerned ${ }^{12}$. In our study, people with type 2 diabetes had a poor glycemic condition with a mean (SD) baseline HbA1c of $9.7(1.8) \%(\approx 83 \mathrm{mmol} / \mathrm{mol})$ 
Table 3 Baseline characteristics of the study population according to the glycemic goal as targeted by the treating physician

HbA1c level targeted by the physician

\begin{tabular}{|c|c|c|c|c|c|}
\hline Study populations & $\begin{array}{l}<6.5 \% \\
(\mathrm{~N}=117)\end{array}$ & $\begin{array}{l}6.5-7 \% \\
(\mathrm{~N}=698)\end{array}$ & $\begin{array}{l}7-7.5 \% \\
(\mathrm{~N}=1852)\end{array}$ & $\begin{array}{l}>7.5 \% \\
(\mathrm{~N}=421)\end{array}$ & $\begin{array}{l}\text { Unknown } \\
(\mathrm{N}=3)\end{array}$ \\
\hline Age (years) mean (SD) & $52.1(9.3)$ & $51.6(10.3)$ & $54.8(10.5)$ & $57.2(10.9)$ & $54.3(12.2)$ \\
\hline Gender, male (\%) & 56.4 & 54.4 & 51.9 & 53.7 & 100 \\
\hline Health coverage (\%) & 45.3 & 46.7 & 52.3 & 53.4 & 66.7 \\
\hline Duration of diabetes (years) mean (SD) & $7.3(6.3)$ & $8.5(6.6)$ & $10.4(6.7)$ & $11.5(7.3)$ & $5.7(5.7)$ \\
\hline $\mathrm{BMI} \mathrm{kg} / \mathrm{m}^{2}$ mean (SD) & $27.5(5.2)$ & $28.4(5.2)$ & $28.9(5.6)$ & $28.7(5.2)$ & $26.3(2.2)$ \\
\hline $\mathrm{BMI} \geq 30 \mathrm{~kg} / \mathrm{m}^{2}(\%)$ & 29.8 & 35.0 & 37.0 & 37.4 & 0.0 \\
\hline BMI 25-30 kg/m² (\%) & 36.0 & 38.1 & 38 & 39.3 & 50 \\
\hline Any diabetes complications (\%) & 33.3 & 52.9 & 56.4 & 57.2 & 33.3 \\
\hline Microvascular complications (\%) & 87.2 & 90.0 & 87.0 & 88.4 & 100 \\
\hline Macrovascular complications (\%) & 28.2 & 34.1 & 30.6 & 37.3 & 100 \\
\hline $\operatorname{HBP}(\%)$ & 49.6 & 52.9 & 62.5 & 66.9 & 66.7 \\
\hline Dyslipidemia (\%) & 49.6 & 57.0 & 57.0 & 64.0 & 66.7 \\
\hline 10 year CHD mean (SD)/median (\%) & $13.6(10.9)$ & $16.6(14.0)$ & $18.3(14.2)$ & $24.0(16.1)$ & $18.0(21.9)$ \\
\hline Diabetes education, (\%) & 47.0 & 59.7 & 63.9 & 65.5 & 66.7 \\
\hline Structured courses of diabetes education, yes (\%) & 5.5 & 2.2 & 1.2 & 1.1 & 0.0 \\
\hline Glucometer, yes (\%) & 42.7 & 51.5 & 61.9 & 68.2 & 100 \\
\hline SMBG use (\%) & 94.0 & 88.0 & 92.7 & 89.9 & 100 \\
\hline Routinely SMBG use (every day) (\%) & 61.7 & 27.4 & 34.4 & 35.3 & 0.0 \\
\hline $\begin{array}{l}\text { Cost of strips is a limiting factor for SMBG use } \\
\text { (yes/no) }\end{array}$ & 32.0 & 46.6 & 45.4 & 37.5 & 66.7 \\
\hline Last $\mathrm{HbA} 1 \mathrm{c}$ measurement (\%) mean (SD) & $8.6(1.5)$ & $9.3(1.7)$ & $9.7(1.8)$ & $10.7(1.7)$ & $7.6(2.1)$ \\
\hline $\mathrm{HbA} 1 \mathrm{c}<7 \%(\%)$ & 16.5 & 3.6 & 1.4 & 0.2 & 33.3 \\
\hline $\begin{array}{l}\text { Number of people with severe hypoglycemia } \\
\text { within last } 3 \text { months } n(\%)\end{array}$ & 0.0 & $11(21.2)$ & $31(16.7)$ & $5(10.2)$ & \\
\hline $\begin{array}{l}\text { Number of emergency room visits mean (SD)/ } \\
\text { median }\end{array}$ & $\begin{array}{l}0.1(0.3) / \\
0.0\end{array}$ & $0.1(0.4) / 0.0$ & $\begin{array}{l}0.1(0.6) / \\
0.0\end{array}$ & $0.1(0.4) / 0.0$ & - \\
\hline
\end{tabular}

BMI, body mass index; CHD, coronary heart disease; HbA1c, glycemic hemoglobin A1c; HBP, high blood pressure; SMBG, self-monitoring blood glucose.

and almost none of them achieved the HbAlc $<7 \%$ target $(53 \mathrm{mmol} / \mathrm{mol})$ in the last 3 months before treatment initiation. Microvascular diabetes-related complications were observed in $87.9 \%$ of the study population. The median estimated 10 year risk of CHD was $14.6 \%$ and thus was comparable with those previously described in the UKPDS study $(6.1 \%-16.5 \%) \%)$ and another survey ( $11 \%$ in women to $21 \%$ in men). ${ }^{13} 14$ These findings were a call to action for achieving a better glycemic control and consequently expected better clinical outcomes on the long term. At the end of inclusion visit, all people were prescribed either insulin alone $(14.6 \%)$ or in combination with OADs $(85.4 \%)$; the preferred insulin dosing regimen was basal insulin alone $(71.2 \%)$ and then the basal bolus regimen with basal plus prandial insulin $(25.1 \%)$. Adherence to therapy was high with $85 \%$ of patients $(1569 / 1849)$ still on basal insulin glargine at the end of the study period at 12 months. The study findings suggest that intensifying the treatment of patients with type 2 diabetes by basal insulin initiation and titration, or intensification resulted in a decreased HbAlc of $2 \%$ points over 12 months. These results can influence positively patients outcome as a linear relationship between absolute change in $\mathrm{HbAlc}$ and mortality has been identified in subjects with an index $\mathrm{HbAlc}>8 \%$ (64 mmol/ mol) the greatest decline in HbAlc being associated with the lowest mortality. ${ }^{15}$

The reasons for having conducted the study were multiple. To date, there is still a large population of severely uncontrolled diabetes $(45 \%-75 \%$ of uncontrolled patients worldwide $^{16-20}$ despite several treatments and current (ADA/EASD position statement ${ }^{7}$ for the management of type 2 diabetes. Moreover, the insulin initiation or intensification by titration can be delayed in practice because of clinical inertia in patient follow-up defined as "failure of healthcare providers to initiate or intensify therapy when 
14

12

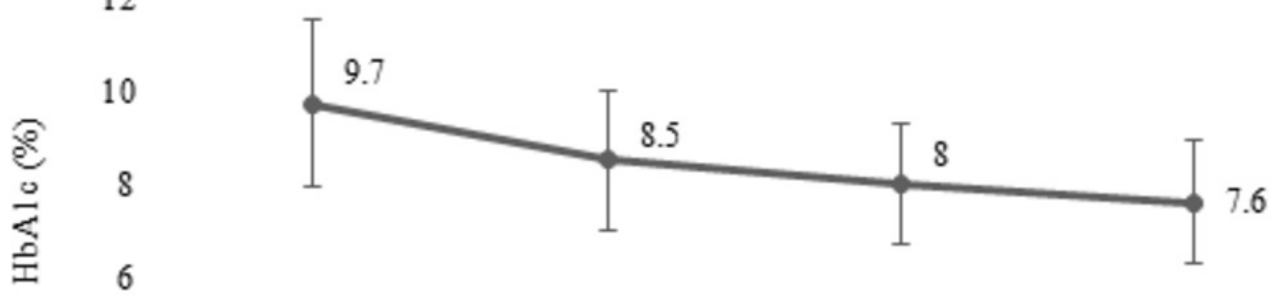

4

2

0

\section{Baseline $\quad 3$ months $\quad 6$ months 12 months}

Figure 2 Change in the glycemic hemoglobin A1c (HbA1c) during the 12-month study duration (mean $\pm 95 \% \mathrm{Cl})$.

indicated ${ }^{21}$; Khunti et a $t^{22}$ reported that only $30.9 \%$ of clinically eligible patients for intensification (HbAlc $\geq 7.5 \%$ (58 $\mathrm{mmol} / \mathrm{mol}$ ) ) received treatment intensified with a median time of 3.7 years from initiation of basal insulin until intensification. In addition, older age, a longer time since diabetes diagnosis, and more comorbidities could significantly increase the delay in the time to intensification. ${ }^{22}$ Another phenomenon termed 'psychological insulin resistance' IR) is linked to patient reluctance toward insulin regimen explaining the possible delay for starting and/or intensifying insulin therapy leading to prolonged periods of poor glycemic control. ${ }^{22}{ }^{23}$ More than one-quarter of insulin-naive patients with type 2 diabetes reported to reject the insulin regimen initiation once it is prescribed. ${ }^{24}$ The fear of hypoglycemia as well as concerns relative to weight gain reported by the patients but also by some physicians after having increased doses of insulin could be barriers to insulin treatment. ${ }^{22-25}$ Non-adherence to treatment with insulins seemed to play also key role in the poor glycemic control due to several explanations. The patient does not necessarily accept injectable route of the insulin regimen and can experience needle anxiety. Compared with men and whites, women and Asians reported a greater fear of injection in the context of insulin initiation. ${ }^{25}$ The number of administrations, need of self-injections, necessity to monitor the blood glucose once a day or more and to have a clean place for storing products may lead to patient inconvenience and missing injections. ${ }^{22}$ Achieving optimal glycemic control in patients with type 2 diabetes by initiating insulin therapy can be also delayed due to socioeconomical barriers; high costs of medications can lead to a reduction of doses since access to treatments and healthcare systems are not the same everywhere.

Regarding the primary endpoint, age, Caucasian ethnicity, shorter duration of diabetes and lower HbAlc at baseline were predictors for achieving glycemic goal as targeted by the treating physician at 6 and 12 months. The same trends were already found in the literature for some of these factors such as longer duration of the disease positively associated with uncontrolled diabetes status, ${ }^{26}$ and initial HbAlc reported as one of the most important success predictor. ${ }^{27}$ Similarly another study conducted in Japan confirmed our data as the authors revealed that shorter diabetes duration ( $<1$ year), lower HbAlc $(<8.5 \%$ $(69 \mathrm{mmol} / \mathrm{mol}))$, and no retinopathy at baseline were significantly associated with a higher rate of achieving the target HbA1c in insulin-naive patients who started therapy with insulin glargine plus OADs ${ }^{28}$ However, our findings differed from a previous report ${ }^{27}$ in which age showed no effects. In our survey, glycemic achievers were significantly older than non-achievers (median age: 57 vs 55 years, respectively), and age appeared to be a significant positive (but not a strong) predictive factor of glycemic control (OR 1.02; $\mathrm{p}=0.0001)$. Findings of this study suggest that poor diabetes education seemed to be a predictive factor of glycemic control. Data about education are conflicting. ${ }^{29} 30$ However, education program delivered by diabetes educators may promote medication adherence for better glycemic control by reducing hospital readmissions. ${ }^{29}$ Moreover, hypertension was identified as a significant predictor of poor glycemic control in this study. This finding was consistent with data found in the literature ${ }^{30}{ }^{31}$ Hypertension is a frequent comorbidity in patients with type 2 diabetes and should be managed by aggressive treatment as well as other comorbid disease conditions to increase the likelihood to achieve good glycemic control and to reduce the burden of CVD. ${ }^{32}$

We also looked at the characteristics of the patients for whom the treating physician was considering HbAlc target $<6.5 \%(48 \mathrm{mmol} / \mathrm{mol})$ instead of HbAlc target $>7.5 \%(58 \mathrm{mmol} / \mathrm{mol})$. Unsurprisingly, the severity of diabetes (long duration of disease, high rate of macrovascular complications) associated with a pejorative $\mathrm{CV}$ risk as illustrated by the 10-year CHD score was found as the physicians' determinants for choosing a high HbAlc target $(\mathrm{HbAlc}>7.5 \%)$. This finding is aligned with the 
conclusions of the landmark ${ }^{33} 34$ studies claiming for individualized glycemic goals and precaution in terms of glycemic reduction for the patients who are exposed to a more severe condition. ${ }^{35}$

Therefore, in addition to the normalization of the possible identified risk factors, it appears necessary to treat early with insulin and intensify the treatment so that a large number of patients reach an optimal glycemic level, decreasing the risk for CVD according to the UKPDS study. ${ }^{9}$ To date, intensive glucose control by lowering the glycated hemoglobin value to $6.5 \%$ is understood to prevent microvascular ${ }^{36}$ and macrovascular complications $^{34}$ in patients with type 2 diabetes. Evidence suggests that early treatment intensification helps a significant proportion of patients achieving a sustained glycemic control (glycemic goal of HbA1c $\leq 7.0 \%$ (53 mmol/ mol) $)^{37}$ and may help lowering rates of diabetes-related complications, given that a 1 year delay in receiving intensification treatment was reported to be associated with significantly increased risk of macrovascular events such as stroke by $51 \%$ (HR, 95\% CI 1.25 to 1.83 ) or heart failure by $64 \%$ (HR, $95 \%$ CI 1.40 to 1.91 )..$^{38}$

Indeed, it seems urgent to improve the management of patients with type 2 diabetes. The more the time passesd the less powerful the tools. Now that the possible causes of this lack of attractiveness for initiating or continuing insulin therapy had been already identified, ${ }^{222425}$ it seems necessary to set up several tools preventing the patient non-acceptability. Several authors ${ }^{23} 39$ investigated some barriers that can be easily overcome through an interprofessional medical approach using appropriate and new education tools, providing explanations on devices for injections, or the use of insulin-specific prescription forms to improve adherence to treatment. The healthcare providers should adopt a patient-centered approach ${ }^{11}$ and impose the patient to follow hygiene-dietetic rules and regular physical activity. Moreover, new therapies or combinations of existing therapies should aim to address the need for better type 2 diabetes management by demonstrating effective glycemic control using a physiological approach (targeting both FPG and PPG), with more patients achieving HbAlc targets, which may help mitigate the risk of diabetes-related microvascular and/ or macrovascular complications.

These study observations suggest that safety findings were rather satisfactory under antidiabetic therapy with insulin therapy over 12 months. There were no new safety concerns regarding basal insulin glargine or insulin glulisine. These findings were consistent with data found in the literature showing a low risk of hypoglycemia and weight gain in patients with type 2 diabetes treated with basal insulin associated with $0 / 1 \mathrm{OAD}^{37}$ as incidence of hypoglycemia was low $(0.3 \%)$ in our survey, and no marked changes in body weight and vital signs were observed from baseline to the end of the survey (12 months).

Strength of this study are its large subset of adults (>18 years) with type 2 diabetes inadequately controlled (ie, more than 2000 eligible patients type 2 diabetes) included in many countries from a wide geographical area. The actual population reflects real-life clinical practice and partially avoids the selection bias that characterizes randomized clinical trials. The analysis of predictive factors of glycemic control was performed in taking into account many clinical and non-clinical variables, which improves its reliability. This study had few inclusion and exclusion criteria that enhances its applicability to broader populations. However, the present study has some limitations owing to its observational design. The HbA1c target level was established by the treating physician according to his/her clinical practice; this choice could be subjective and different between practitioners. Furthermore, regular HbAlc measurements were not available for about $22 \%$ of the total analysis population at 6 and 12 months of follow-up that may have a slight influence on the observed results.

In conclusion, in people with type 2 diabetes inadequately controlled starting or intensifying their insulin dosing regimen showed an important decrease in HbAlc. Insulin regimen therapy initiated and/or intensified allowed, then, patients to achieve a better glycemic control at 12 months compared with baseline. No specific warnings were identified concerning the safety of insulin glargine and insulin glulisine. The risk of hypoglycemia and weight gain was limited. This large study confirmed that some well-known predictive factors (shorter type 2 diabetes duration, lower baseline HbA1c, no hypertension) could influence the patient glycemic outcome and prognosis.

\section{Author affiliations}

${ }^{1}$ Department of Endocrinolog, Erfan Hospital, Jeddah, Saudi Arabia

${ }^{2}$ Department of Endocrinology, Zalka, Haroun Hospital, Beirut, Lebanon

${ }^{3}$ Section of Diabetes, Endocrinology \& Metabolism, Department of Medicine, The

Aga Khan University Hospital, Karachi, Pakistan

${ }^{4}$ Department of Endocrinology, Bangabandhu Sheikh Mujib Medical University, Dhaka, Bangladesh

${ }^{5}$ Department of Endocrinology, Dubai Diabetes Center, Dubai, UAE

${ }^{6}$ Department of Endocrinology, Sanofi, Paris, France

${ }^{7}$ Department of Endocrinology, Research Center for Prevention of Cardiovascular Disease, Institute of Endocrinology \& Metabolism, Iran University of Medical Sciences, Tehran, Iran

${ }^{8}$ Department of Endocrinology, Internal Medicine D, Hasharon Hospital Rabin Medical Center, Sackler School of Medicine, Tel Aviv University, Tel Aviv, Israel ${ }^{9}$ Department of Endocrinology, Apollo Gleneagles Hospitals, Kolkata, West Bengal, India

Acknowledgements The authors would like to thank all investigators involved in the study, POPSICUBE-FOVEA CRO (Montigny-le-Bretonneux) for the logistics and data analyses, and Valérie Patin (Valor One) for her assistance in medical writing, funded by Sanofi.

Contributors All authors were involved in the analysis and interpretation of data, contributed to the discussion and writing of the manuscript, and approved the final version of the article.

Funding The study and data analysis was sponsored by Sanofi, Paris, France.

Competing interests $\mathrm{KD}$ is employee at Sanofi. MF, YO, AAIM, AH and DD were national investigators for the study in their respective countries. AAIM, YO, NI, MF, AH, MM, TC received support from Sanofi to discuss the design, analysis, and interpretation of the study.

Patient consent Not required. 
Ethics approval Ethics approval was obtained from institutional boards of each country.

Provenance and peer review Not commissioned; externally peer reviewed.

Data statement № additional data available.

Author note GOAL (non-interventional on the therapeutic strategy). There was no EUDRACT or NCT number as for clinical trials. Protocol was not disclosed to CT. gov. Study identifications numbers were: ClubNet number (LANTUR06314) and the OPTIMEnumber (OBS13527).

Open access This is an Open access article distributed in accordance with the Creative Commons Attribution Non Commercial (CC BY-NC 4.0) license, which permits others to distribute, remix, adapt, build upon this work non-commercially, and license their derivative works on different terms, provided the original work is properly cited, appropriate credit is given, any changes made indicated, and the use is non-commercial. See: http://creativecommons.org/licenses/by-nc/4.0/.

\section{REFERENCES}

1. International Diabetes Federation. IDF Diabetes Atlas - Seventh Edition [online]. 2015. https://www.idf.org/e-library/epidemiologyresearch/diabetes-atlas.html (accessed 19 Dec 2017).

2. World Health Organization (WHO). Global Report on Diabetes [online]. World HealthOrganization, Geneva (Switzerland). 2016 http://apps.who.int/iris/bitstream/10665/204871/1/9789241565257 eng.pdf (accessed 19 Dec 2017).

3. van Dieren S, Beulens JW, van der Schouw YT, et al. The global burden of diabetes and its complications: an emerging pandemic. Eur J Cardiovasc Prev Rehabil 2010;17(Suppl 1):S3-8.

4. Mathers CD, Loncar D. Projections of global mortality and burden of disease from 2002 to 2030. PLoS Med 2006;3:e442.

5. Sarwar N, Gao P, Seshasai SR, et al. Diabetes mellitus, fasting blood glucose concentration, and risk of vascular disease: a collaborative meta-analysis of 102 prospective studies. Lancet 2010;375:2215-22.

6. Nathan DM, Buse JB, Davidson MB, et al. Medical management of hyperglycemia in type 2 diabetes: a consensus algorithm for the initiation and adjustment of therapy: a consensus statement of the American Diabetes Association and the European Association for the Study of Diabetes. Diabetes Care 2009;32:193-203.

7. Diabetes Control and Complications Trial Research Group, Nathan DM, Genuth S, et al. The effect of intensive treatment of diabetes on the development and progression of long-term complications in insulin-dependent diabetes mellitus. N Engl J Med 1993;329:977-86.

8. Stratton IM, Adler Al, Neil HA, et al. Association of glycaemia with macrovascular and microvascular complications of type 2 diabetes (UKPDS 35): prospective observational study. BMJ 2000;321:405-12.

9. Gerstein HC, Pogue J, Mann JF, et al. The relationship between dysglycaemia and cardiovascular and renal risk in diabetic and non-diabetic participants in the HOPE study: a prospective epidemiological analysis. Diabetologia 2005;48:1749-55.

10. Inzucchi SE, Bergenstal RM, Buse JB, et al. Management of hyperglycemia in type 2 diabetes, 2015: a patient-centered approach: update to a position statement of the American Diabetes Association and the European Association for the Study of Diabetes. Diabetes Care 2015;38:140-9.

11. Khunti K, Wolden ML, Thorsted BL, et al. Clinical inertia in people with type 2 diabetes: a retrospective cohort study of more than 80,000 people. Diabetes Care 2013;36:3411-7.

12. Chan JC, Gagliardino JJ, Baik SH, et al. Multifaceted determinants for achieving glycemic control: the International Diabetes Management Practice Study (IDMPS). Diabetes Care 2009;32:227-33.

13. Bannister CA, Poole CD, Jenkins-Jones $S$, et al. External validation of the UKPDS risk engine in incident type 2 diabetes: a need for new type 2 diabetes-specific risk equations. Diabetes Care 2014;37:537-45.

14. Sandbaek A, Griffin SJ, Rutten G, et al. Stepwise screening for diabetes identifies people with high but modifiable coronary heart disease risk. The ADDITION study. Diabetologia 2008;51:1127-34.

15. Skriver MV, Sandbæk A, Kristensen JK, et al. Relationship of $\mathrm{HbA1c}$ variability, absolute changes in $\mathrm{HbA} 1 \mathrm{c}$, and all-cause mortality in type 2 diabetes: a Danish population-based prospective observational study. BMJ Open Diabetes Res Care 2015;3:e000060.

16. Alba LH, Bastidas C, Vivas JM, et al. [Prevalence of glycemic contro and associated factors in type 2 diabetes mellitus patients at the Hospital Universitario de San Ignacio, Bogotá-Colombia]. Gac Med Mex 2009;145:469-74.
17. Selvin E, Parrinello CM, Sacks DB, et al. Trends in prevalence and control of diabetes in the United States, 1988-1994 and 1999-2010. Ann Intern Med 2014;160:517-25.

18. Alvarez Guisasola F, Mavros P, Nocea G, et al. Glycaemic control among patients with type 2 diabetes mellitus in seven European countries: findings from the Real-Life Effectiveness and Care Patterns of Diabetes Management (RECAP-DM) study. Diabetes Obes Metab 2008;10(Suppl. 1):8-15.

19. Noureddine H, Nakhoul N, Galal A, et al. Level of A1C control and its predictors among Lebanese type 2 diabetic patients. Ther Adv Endocrinol Metab 2014;5:43-52.

20. Al-Rasheedi AA. Glycemic Control among Patients with Type 2 Diabetes Mellitus in Countries of Arabic Gulf. Int J Health Sci 2015;9:339-44

21. Khunti S, Davies MJ, Khunti K. Clinical inertia in the management of type 2 diabetes mellitus: a focused literature review. $\mathrm{Br} J$ Diabetes 2015;15:65-9.

22. Khunti K, Nikolajsen A, Thorsted BL, et al. Clinical inertia with regard to intensifying therapy in people with type 2 diabetes treated with basal insulin. Diabetes Obes Metab 2016;18:401-9.

23. Korytkowski M. When oral agents fail: practical barriers to starting insulin. Int J Obes Relat Metab Disord 2002;26(Suppl. 3):S18-24.

24. Polonsky WH, Fisher L, Guzman S, et al. Psychological insulin resistance in patients with type 2 diabetes: the scope of the problem. Diabetes Care 2005;28:2543-5.

25. Nam S, Chesla C, Stotts NA, et al. Factors associated with psychological insulin resistance in individuals with type 2 diabetes. Diabetes Care 2010;33:1747-9.

26. Yousefzadeh G, Shokoohi M, Najafipour H. Inadequate control of diabetes and metabolic indices among diabetic patients: A population based study from the Kerman Coronary Artery Disease Risk Study (KERCADRS). Int J Health Policy Manag 2014;4:271-7.

27. Sarkadi A, Rosenqvist U. Field test of a group education program for type 2 diabetes: measures and predictors of success on individual and group levels. Patient Educ Couns 2001;44:129-39.

28. Kadowaki T, Ohtani T, Odawara M. Baseline predictive factors for glycemic control in Japanese type 2 diabetes patients treated with insulin glargine plus oral antidiabetic drugs: ALOHA study subanalysis. Diabetol Int 2013;4:16-22.

29. Healy SJ, Black D, Harris C, et al. Inpatient diabetes education is associated with less frequent hospital readmission among patients with poor glycemic control. Diabetes Care 2013;36:2960-7.

30. Rajeshwar Y, Eticha T, Mulu A, et al. Factors Associated with Poor Glycemic Control in Type 2 Diabetic Patients Investigated at Ayder Referral Hospital Mekelle, Ethiopia. ljppr Human 2016;6:160-71.

31. Crowley MJ, Holleman R, Klamerus ML, et al. Factors associated with persistent poorly controlled diabetes mellitus: clues to improving management in patients with resistant poor control. Chronic IIIn 2014;10:291-302.

32. Kendall DM, Bergenstal RM. Comprehensive management of patients with type 2 diabetes: establishing priorities of care. Am J Manag Care 2001;7(10 Suppl. 10):S327-43. quiz S344-8.

33. Action to Control Cardiovascular Risk in Diabetes Study Group, Gerstein HC, Miller ME, Byington RP, et al. Effects of intensive glucose lowering in type 2 diabetes. $N$ Engl $\mathrm{J} \mathrm{Med}$ 2008;358:2545-59.

34. ADVANCE Collaborative Group, Patel A, MacMahon S, Chalmers $\mathrm{J}$, et al. Intensive blood glucose control and vascular outcomes in patients with type 2 diabetes. N Engl J Med 2008;358:2560-72.

35. Cefalu WT. Glycemic targets and cardiovascular disease. N Engl J Med 2008;358:2633-5.

36. UK Prospective Diabetes Study Group (UKPDS). Intensive bloodglucose control with sulphonylureas or insulin compared with conventional treatment and risk of complications in patients with type 2 diabetes (UKPDS 33). UK Prospective Diabetes Study (UKPDS) Group. Lancet 1998;352:837-53.

37. Fonseca V, Gill J, Zhou R, et al. An analysis of early insulin glargine added to metformin with or without sulfonylurea: impact on glycaemic control and hypoglycaemia. Diabetes Obes Metab 2011;13:814-22

38. Paul SK, Klein K, Thorsted BL, et al. Delay in treatment intensification increases the risks of cardiovascular events in patients with type 2 diabetes. Cardiovasc Diabetol 2015;14:100.

39. Ali A, Cheng $\mathrm{AY}, \mathrm{Yu} \mathrm{CH}$. Breaking down barriers to initiating insulin: Insulin prescription pad. Can Fam Physician 2015;61:445-7.

40. Food and Drug Administration. 2016.Collection of Race and Ethnicity Data in Clinical Trials. Guidance for Industry and Food and Drug Administration Staff https://www.fda.gov/ucm/groups/fdagovpublic/@fdagov-afda-gen/documents/document/ucm126396.pdf (accessed 03 Apr 2018). 